\title{
Effect of 5-ALA-PDT on VEGF and PCNA expression in human NPC-bearing nude mice
}

\author{
YING XIE $^{1 *}$, ZHENG-BO WEI $^{2 *}$, ZHE ZHANG $^{3}$, WENSHENG WEN ${ }^{3}$ and GUANG-WU HUANG ${ }^{3}$ \\ Department of ${ }^{1}$ GuangXi Experimental Center of Medical Sciences, ${ }^{2}$ Facilitated Tumor Hospital, \\ ${ }^{3}$ First Affiliated Hospital of GuangXi Medical University, Nanning 530021, P.R. China
}

Received June 22, 2009; Accepted August 18, 2009

DOI: $10.3892 /$ or_00000576

\begin{abstract}
Photodynamic therapy (PDT) is a promising treatment for nasopharyngeal carcinoma. However, recurrence and metastasis of the tumor after PDT remains problematic. In this study we investigated VEGF and PCNA expression in tumor tissues after 5-ALA-PDT. BALB/c nude mice with NPC tumors of similar size were randomly assigned to three groups $(\mathrm{n}=10$ each). In the two treatment groups, mice were administrated 5-ALA intratumorally at a dose of $100 \mathrm{mg} / \mathrm{kg}$ and $3-3.5 \mathrm{~h}$ prior to laser irradiation $\left(630 \mathrm{~nm}, 100 \mathrm{~J} / \mathrm{cm}^{2}\right.$, $100 \mathrm{~mW} / \mathrm{cm}^{2}$ ). The mice in one of the treatment groups were sacrificed at $24 \mathrm{~h}$ after PDT. The other treatment group and control group mice were sacrificed 14 days after PDT, and the tumor weights were determined for all three groups. Mean tumor weights at 14 days after PDT were $1.353 \pm 0.204 \mathrm{~g}$ in the treatment group and $3.124 \pm 0.380 \mathrm{~g}$ in the control group $(p<0.001)$. Results showed the VEGF level in tumor tissues at $24 \mathrm{~h}$ after PDT was slightly higher than that in the control group, while it was down-regulated at 14 days after PDT. The PCNA level was not significantly different in tumor tissues among the three groups, but it was lower in degenerated tumor cells $24 \mathrm{~h}$ after PDT. Our results suggest that VEGF may play a role in tumor recurrence and metastasis following PDT. Residual tumor cells escaped from PDT is the main reason for tumor recurrence.
\end{abstract}

\section{Introduction}

Nasopharyngeal carcinoma (NPC) is a non-lymphomatous, squamous-cell carcinoma prevalent in Southern China, especially in GuangDong and GuangXi provinces. Radio-

Correspondence to: Professor Guang-Wu Huang, Department of First Affiliated Hospital of GuangXi Medical University, Nanning 530021, P.R. China

E-mail: hgw1288@yahoo.com.cn

${ }^{*}$ Contributed equally

Key words: 5-aminolevulinic acid (5-ALA), photodynamic therapy, nasopharyngeal carcinoma, VEGF, PCNA therapy is the standard treatment for NPC, but it still has a high recurrence rate (1). The 5-year survival rate is only approximately $50 \%$ after radiotherapy and chemotherapy (1). NPC often develops undesirable complications after radiotherapy, mainly because it is located at the base of skull, where it lies in close proximity to radiation-sensitive organs, including the brain stem, spinal cord, pituitary-hypothalamic axis, temporal lobes, eyes, middle and inner ears, and parotid glands. Since NPC tends to infiltrate and spread towards these dose-limiting organs, it is even more difficult to protect these parts of the body during treatment (2). Thus, development of novel therapeutic approaches to NPC is necessary.

Since photodynamic therapy (PDT) was first developed in the 1980s $(3,4)$, it has attracted interest for its selectivity, low toxicity, rapid effects, and reliable effectiveness. PDT is a promising modality for cancer treatment that has been used successfully in thousands of tumor patients worldwide $(5,6)$. In addition, the application of PDT using a first-generation photosensitizer to treat NPC have been encouraging $(7,8)$. In fact, PDT using the photosensitizer 5-aminolevulinic acid (5-ALA) has proven to be an effective method to treat malignant tumors in both animal and human $(9,10)$. It has several advantages, such as greater tumor specificity and rapid clearance from the body $(11,12)$, as well as tolerability such that repeat administrations have no effect on subsequent treatment and local injections have no adverse effects (13). In vitro studies have shown that ALA and ALA hexyl estermediated PDT can destroy directly NPC/CNE2 cells in vitro (14). In general, PDT outcome depends on the type and amount of photosensitizer absorbed by the tumor, the wavelength of the light, the depth of light penetration into the tumor, and light energy delivered. However, regardless of the photosensitizer used, tumor recurrence and metastasis after PDT remains problematic despite a good initial response. The reasons for tumor recurrence and metastasis after PDT remain unclear (15).

In discussing tumor recurrence following PDT, it is important to evaluate not only the extent of irradiation and malignancy but also cell proliferative potential, which can be studied through the expression of proliferating cell nuclear antigen (PCNA) (15). PCNA is a $36-\mathrm{kDa}$ nuclear polypeptide synthesized during the late $\mathrm{G} 1$ to $\mathrm{S}$ phase that acts as a homotrimer and helps increase the processivity of leadingstrand synthesis during DNA replication (16). PCNA is also a cofactor for DNA polymerase $\delta$, which is required for DNA 
replication and cell proliferation (17). Previous studies have demonstrated that a high level of PCNA expression is associated with poor prognosis in many solid tumors $(17,18)$.

Tumor metastasis is another important factor that may mitigate PDT tumoricidal effect. Momma et al (14) have reported an increase in the number of lung metastases following subcurative BPD (benzoporphyrin derivative)-PDT in a highly aggressive prostate cancer model. In the preliminary study we found that nude mice bearing CNE2 NPC tumors have distant metastasis following 5-ALA (aminolevulinic acid)-PDT (data not shown). However, reports from several other laboratories suggest that PDT decreases metastasis compared to results obtained with surgery $(19,20)$. Following in vitro HPD (hematoporphyrin)-based PDT, adhesion to extracellular matrix (ECM) and metastatic potential declined in DHD-K12-cultured colon carcinoma cells (21), and the same research group observed similar results in vivo (22). Moreover, intravenous or subcutaneous (s.c) injection of these PDT-treated cells into rats resulted in a low number of lung metastases compared with injection of untreated cells (22). Taken together, these results suggest that the probability of tumor metastasis following PDT depends not only on the tumor type but also on the photosensitizer.

Vascular endothelial growth factors (VEGFs) are a group of extremely important molecules in tumor metastasis. Commonly the term VEGF refers to VEGFA (vascular endothelial growth factor A), which is a member of the PDGF/ VEGF growth factor family and that is often found as a disulfide-liked homodimer. This protein is a glycosylated mitogen that acts specifically on endothelial cells and has various effects, including increasing vascular permeability inducing angiogenesis, vasculogenesis and endothelial cell growth promoting cell migration and inhibiting apoptosis (23). The angiogenesis associated with human tumors is likely a central component in promoting tumor growth and metastatic potential. Therefore, the detection of VEGF expression can help in understanding tumor metastasis potential following PDT. A few reports also exist on the change in the synthesis and secretion of VEGF following subcurative PDT for different periods and with different photosensitizers (24-26).

Application of 5-ALA has not been reported in treatment of NPC cell-bearing animals or in patients with NPC. In addition, regulation of VEGF expression following 5-ALAPDT is unclear.

The present study aimed to examine the effect of 5-ALAPDT on the expression of VEGF and PCNA in NPC tumors, in order to understand better the recurrence and metastasis following PDT, as well as to serve as a basis for further studies.

\section{Materials and methods}

Animals. In this study we used male BALB/c athymic nude mice, aged 5-6-weeks and weighing 17-22 g ( $\mathrm{n}=30)$. The mice were purchased from the Institute of Laboratory Animal Sciences of the Chinese Academy of Medical Sciences (CAMS) and Peking Union Medical College (PUMC). All the animals used were bred at the nude rodent facility of the Animal Center of GuangXi Medical University, and the experiments performed according to the University ethics guidelines. They were housed five per cage, and maintained under specific pathogen-free conditions.

Cell line and tumors. Poorly differentiated human nasopharyngeal carcinoma CNE2 cells were cultured in Iscove's modified Dulbecco's medium (IMDM), containing 10\% fetal bovine serum, penicillin $\mathrm{G}(100 \mathrm{kU} / \mathrm{l})$, and streptomycin $(0.1 \mathrm{~g} / 1)$ at $37^{\circ} \mathrm{C}$ in a $5 \% \mathrm{CO}_{2}$ atmosphere. Then, CNE2 cells $\left(2-5 \times 10^{6}\right)$ suspended in $0.2 \mathrm{ml}$ of PBS were implanted s.c. in the right flank of the mice. The tumor volume was calculated using the following formula (27): $\mathrm{V}=\pi / 6(\mathrm{AxB} x \mathrm{C})$, where $\mathrm{A}, \mathrm{B}, \mathrm{C}$ are three orthogonal diameters of the tumors that were measured every other day using a caliper.

Photodynamic therapy (PDT). PDT was performed on day 10-12 after tumor cell transplantation, after the size of tumors had reached $0.10-0.15 \mathrm{~cm}^{3}$, tumor-bearing mice were randomly divided into three groups (10 animals per group): groups A and B received intratumoral administration of 20\% 5-ALA (Sigma Chemical Co.) at a dose of $100 \mathrm{mg} / \mathrm{kg}$, following by PDT at $3-3.5 \mathrm{~h}$ later $(630 \mathrm{~nm}$, $100 \mathrm{~J} / \mathrm{cm}^{2}, 100 \mathrm{~mW} / \mathrm{cm}^{2}$ ) (28); group $\mathrm{C}$ was the control group and was subjected to the same irradiation but without 5-ALA. The diameter of the irradiating laser beam entirely covered the tumor. The interval between administration of 5-ALA and irradiation was determined based on our preliminary experiments. This early study showed that 5-ALA was mainly taken up by the tumor tissue and the liver of nude mice, and then turned into protoporphyrin IX (PpIX). The concentration of PpIX in tumors was found to reach a peak at 3-3.5 h after administration (data not shown).

At $24 \mathrm{~h}$ after irradiation, the mice in group A were sacrificed. At 14 days after irradiation, the mice in groups $\mathrm{B}$ and $\mathrm{C}$ were sacrificed. Tumor sizes and weights were analyzed statistically using an unpaired Student's t-test.

Haematoxylin and eosin $(H \& E)$ staining. A part of each tumor was excised and fixed in $3.7 \%$ formaldehyde ( $\mathrm{pH} 7.0)$ for routine paraffin embedding. A series of $4-\mu \mathrm{m}$ sections were prepared for each specimen, mounted on polylysinecoated glass slides, and dried overnight on a hot plate at $37^{\circ} \mathrm{C}$ to promote adhesion. H\&E staining was carried out on one section of each specimen.

Immunohistochemical analysis of VEGF and PCNA. Immunostaining of paraffin sections was performed after dewaxing and rehydrating the $4-\mu \mathrm{m}$ sections. For VEGF and PCNA detection, mouse monoclonal primary antibodies specific for VEGF and PCNA (Santa Cruz Biotechnology, CA) were diluted in PBS (1:300 for VEGF and 1:500 for PCNA). Goat anti-mouse IgG-horseradish peroxidase (HRP) (sc-2005, Santa Cruz Biotechnology) was diluted 1:500 in PBS and used as secondary antibody. Sections were examined and scored, using a semiquantitative immunoreactive score (IRS) $(29,30)$. Mean dye intensity was assessed using the following scale: 0 , negative; 1 , low; 2 , middle; and 3 , strong. The percentages of stained cells varied as follows: 0 (negative); 1 (<10\%); 2 (10-50\%); 3 (51-80\%); and 4 (>80\% positive cells). The product of both sums yields a total score ranging from 0 

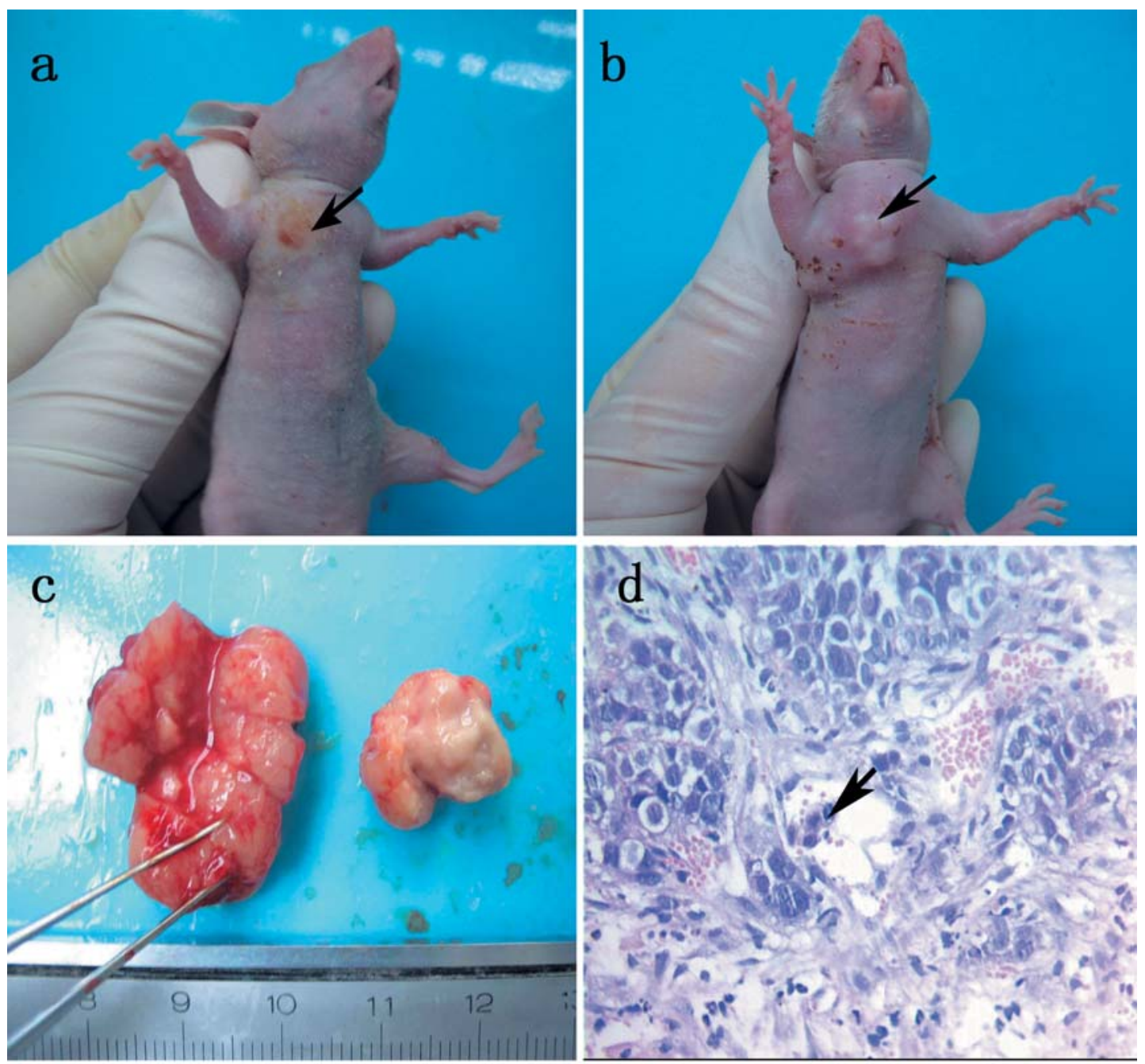

Figure 1. Tumor-bearing mice from the 5-ALA-PDT treatment group and the control group. (a and b) Results on the third day after 5-ALA-PDT. There was a scar in midst of the tumor (black arrow) after 5-ALA-PDT (a), and the size of tumor was much smaller than that in the control group (b) on the same day. (c) Tumor resection at 14 days after PDT, on the left is the tumor in control group without PDT, which is larger than that on the right of PDT-treated one; and the cut surface of tumor in treated group is pale indicating poor blood supply. (d) H\&E staining of slice in PDT-treated group showed a blood vessel was infiltrated by tumor cells (black arrow).

to 12 points. According to the scores, tissues were classified as having weak VEGF and PCNA expression (0-4 points) or strong expression (6-12 points). $\chi^{2}$ tests (two-sided) were used to evaluate significance. A P-value $<0.05$ was taken to indicate statistically significant differences.

Western blotting. Tumor tissue removed from the mice was lysed in $500 \mu \mathrm{l}$ of lysis buffer [-50 mM Tris- $\mathrm{HCl}(\mathrm{pH} 8.0)$, 1 mM EDTA (pH 8.0), 5 mM dithiothreitol (DTT), $2 \%$ sodium dodecylsulfate (SDS)] on ice for $30 \mathrm{~min}$ and sonicated on ice for $30 \mathrm{sec}$. The resulting lysates were clarified by centrifugation. The concentration of the protein in the supernatants was determined with a BCA protein assay (Thermo, USA). Equivalent amounts of protein were separated by $10 \%$ sodium dodecylsulfate-polyacrylamide gel electrophoresis (SDS-PAGE) and then electroblotted onto a polyvinylidene fluoride (PVDF) transfer membranes, blocked with $5 \%$ skimmed milk, and probed with antibodies against VEGF, PCNA or GAPDH (Santa Cruz). After incubation with HRPconjugated goat anti-mouse secondary antibody (Santa Cruz), immunoblots were visualized using enhanced chemiluminescence (Amersham Pharmacia Biotech, Piscataway, USA) (24).

\section{Results}

Effects of 5-ALA PDT in vivo. A 5-ALA dose of $100 \mathrm{mg} / \mathrm{kg}$, an energy dose of $100 \mathrm{~J} / \mathrm{cm}^{2}$ and an irradiation intensity of $100 \mathrm{~mW} / \mathrm{cm}^{2}$ were selected for the in vivo studies. 5-ALA applied by intratumoral injection was generally well tolerated by the mice: body weight and overall health were similar between treated and control mice. The mean size of the tumors before treatment was $0.15 \pm 0.026 \mathrm{~cm}^{3}$ in the 5-ALA-PDT treatment group $(\mathrm{n}=10)$, and $0.151 \pm 0.021 \mathrm{~cm}^{3}$ in the control group $(n=10)$. At $24 \mathrm{~h}$ after irradiation, the tumors in the control group grew faster than those in the 5-ALA-PDT group. The difference in the size of tumors between the control and the experimental groups was significant (Fig. 1a and b). Mean tumor volumes on day 14 after PDT were $0.888 \pm 0.115 \mathrm{~cm}^{3}$ in the treated group $(\mathrm{n}=10)$ and $2.088 \pm 0.184 \mathrm{~cm}^{3}$ in the control 
Table I. Statistical analysis of tumor volume and weight using Student's t-test.

\begin{tabular}{lccc}
\hline Determination of tumor volume and weight & 5-ALA-PDT group $(\mathrm{n}=10)$ & Control group $(\mathrm{n}=10)$ & P-value \\
\hline Tumor volume $\left(\mathrm{cm}^{3}\right)$ 0 day after PDT & $0.150 \pm 0.026$ & $0.151 \pm 0.021$ & $>0.05$ \\
Tumor volume $\left(\mathrm{cm}^{3}\right)$ 3 days after PDT & $0.252 \pm 0.054$ & $0.543 \pm 0.070$ & $1.116 \pm 0.111$ \\
Tumor volume $\left(\mathrm{cm}^{3}\right)$ 7 days after PDT & $0.502 \pm 0.070$ & $2.088 \pm 0.184$ & $<0.001^{\mathrm{a}}$ \\
Tumor volume $\left(\mathrm{cm}^{3}\right)$ 14 days after PDT & $0.888 \pm 0.115$ & $3.124 \pm 0.380$ & $<0.001^{\mathrm{a}}$ \\
Tumor weight $(\mathrm{g}) 14$ days after PDT & $1.353 \pm 0.204$ & $<0.001^{\mathrm{a}}$
\end{tabular}

Data are presented as mean \pm standard deviation of the mean of tumor volume or weight. ${ }^{\text {a }}<0.05$ indicates statistically significant differences.
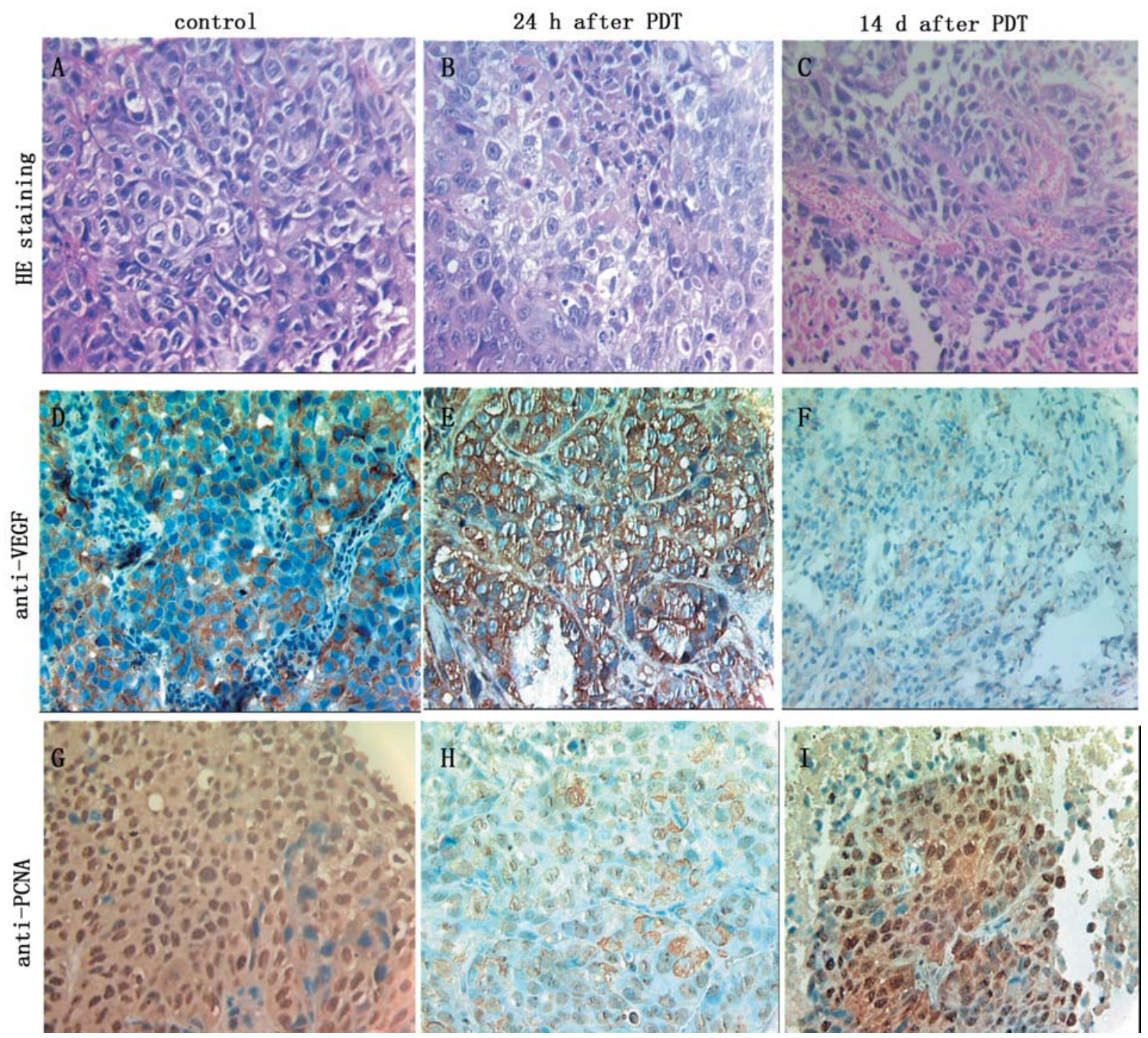

Figure 2. Observed by light microscope $\mathrm{x} 400$. Vacuolar degeneration and necrotic cells were observed at $24 \mathrm{~h}$ after 5-ALA-PDT (B), compare with tumor cells in control group (A). On day 14 after PDT, coagulation necrosis with ambiguous cellar structure can be seen, together with some residual living tumor cells (C). Tumors collected at $24 \mathrm{~h}$ after irradiation showed slightly more intense VEGF staining following PDT (E). But tumors in the day 14 group showed less intense VEGF staining (F) than those of control group (D). PCNA brown staining was significantly concentrated in the nucleolus of tumor cells (G, $\mathrm{H}$ and I). Degenerated tumor cells $24 \mathrm{~h}$ after PDT show slightly less intense of PCNA staining (H), while the other relatively normal tumor cells still showed high-intensity staining.

group $(\mathrm{n}=10)$. Mean tumor weights on day 14 after PDT were $1.353 \pm 0.204 \mathrm{~g}$ in the treated group and $3.124 \pm 0.380 \mathrm{~g}$ in the control group. There were significant differences $(\mathrm{p}<0.001)$ in mean tumor volume and weight between these two groups 
Table II. Protein level detected by immunohistochemistry.

\begin{tabular}{|c|c|c|c|c|c|c|c|}
\hline \multirow[b]{2}{*}{ Groups } & \multirow[b]{2}{*}{ No. } & \multicolumn{2}{|c|}{ VEGF staining } & \multirow[b]{2}{*}{$\mathrm{P}$-value } & \multicolumn{2}{|c|}{ PCNA staining } & \multirow[b]{2}{*}{$\mathrm{P}$-value } \\
\hline & & $\begin{array}{c}\text { Weak }(0-4) \\
(\%)\end{array}$ & $\begin{array}{c}\text { Strong }(6-12) \\
(\%)\end{array}$ & & $\begin{array}{c}\text { Weak }(0-4) \\
(\%)\end{array}$ & $\begin{array}{c}\text { Strong }(6-12) \\
(\%)\end{array}$ & \\
\hline $24 \mathrm{~h}$ after PDT & 10 & $2(20)$ & $8(80)$ & & $3(30)$ & $7(70)$ & \\
\hline 14 days after PDT & 10 & $6(60)$ & $4(40)$ & 0.178 & $1(10)$ & $9(90)$ & 0.089 \\
\hline Control & 10 & $4(40)$ & $6(60)$ & & $0(0)$ & $10(100)$ & \\
\hline
\end{tabular}

P-value according to $\chi^{2}$ test (two-sided) were calculated to determine significant differences in VEGF or PCNA immunoreactivity among the control group, the 24-h ALA-PDT group, and the 14-day ALA-PDT group.

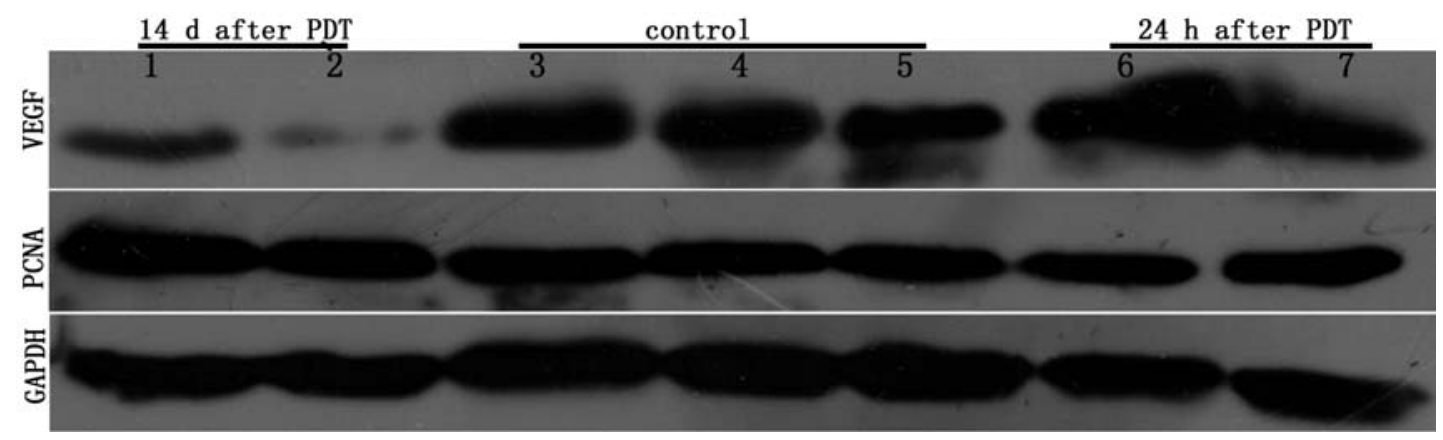

Figure 3. Western blot results. Western blot analyses of VEGF and PCNA and anti-GAPDH as controls. VEGF level was lower in tumor tissues at 14 days after PDT (lanes 1,2) than in the control group (lanes 3, 4, 5). In contrast, there was no significant difference in PCNA levels among the three groups.

after PDT (Table I). The data show that 5-ALA-PDT is effective in slowing the growth of NPC tumors in nude mice, but not in killing all of the tumor cells.

Histological findings. In the control group, there were numerous mitotic tumor cells around the blood vessels and in the peripheral regions of the tumors (Fig. 2A). Only a few scattered necrotic areas were observed in the tumors. Extensive degeneration and pyknotic cells were observed in tumors $24 \mathrm{~h}$ after PDT, and the latter were easily distinguished from the normal tumor cells (Fig. 2B). There were numerous necrotic areas observed on day 14 after PDT, and some residual tumor cell islands were observed (Fig. 2C). $\mathrm{H} \& \mathrm{E}$ staining of slices from the PDT-treated group at $24 \mathrm{~h}$ after irradiation showed that a blood vessel was infiltrated by tumor cells (Fig. 1d).

Immunohistochemistry of VEGF and PCNA. Immunohistochemical analysis was used to compare VEGF and PCNA protein expression in tumor tissues of 5-ALA PDT and control groups. The intensity and quantity of immunohistochemical staining was evaluated using a semiquantitative immunoreactivity score (IRS) $(29,30)$. In VEGF immunohistochemistry, the cytoplasm of VEGF-positive cells was distinguished by brown staining (Fig. 2D and F). VEGF remained significantly concentrated in the tumor cells around the microvessels. Tumors collected $24 \mathrm{~h}$ after irradiation showed slightly more intense VEGF staining following PDT (strong straining in 8/10 samples, Fig. 2E). However, the tumors on day 14 after 5-ALA-PDT showed less intense VEGF staining (strong straining in 4/10 samples) than those of the control group (strong staining in $6 / 10, \mathrm{P}=0.178$, Fig. $2 \mathrm{~F}$ ). In PCNA immunohistochemistry, the nucleus of PCNA-positive cells was distinguished by brown staining. There were numerous necrotic areas observed on day 14 after PDT (Fig. 2I), which indicated effective treatment. The residual tumor cells on day 14 after PDT still showed intense PCNA staining (Fig. 2I). Degenerated tumor cells observed at $24 \mathrm{~h}$ after PDT showed down-regulated PCNA expression compared to controls $(\mathrm{P}=0.089$, Fig. $2 \mathrm{H})$. These results are described in detail in Table II.

Validation by Western blotting. Tissue lysates from three groups were subjected to immunoblotting with anti-VEGF or PCNA antibody, and blots were reprobed with anti-GAPDH to verify equal loading. A surprising finding in this study is the great difference in VEGF levels in the tumor tissues among these three groups. VEGF levels were slightly higher in tumor tissues at $24 \mathrm{~h}$ after PDT than in the control samples. VEGF was down-regulated in tumor tissues on day 14 after PDT. In contrast, PCNA levels showed no significant difference among these three groups, although they were slightly lower in degenerated tumor cells at $24 \mathrm{~h}$ after PDT compared to control samples (Fig. 3). 


\section{Discussion}

ALA-PDT has been shown to be effective against malignant tumors in both animal and human $(9,10)$. But application of 5-ALA has not been reported in treatment of NPC cellbearing animals. Our study is the first to show therapeutic outcomes for treating NPC with ALA-PDT and molecular changes in vivo following the treatment. In the present study we found significant decrease in size of tumor tissue in nude mice treated with ALA-PDT compared to the control, demonstrating that ALA-PDT can effectively induce killing of CNE2 tumor cells.

However, the effect of ALA-PDT on CNE2 cells in our present study is limited, for H\&E staining showed that not all of the tumor cells were killed. At $24 \mathrm{~h}$ after PDT, some of the tumor cells showed necrosis or apoptosis, while surrounding tumor cells appear to be only slightly damaged, indicating that some of the tumor tissue was less affected by ALA-PDT. This subcurative outcome may be due to the non-homogeneous distribution of the photosensitizer and/or of light in the tumor tissue (31). Previous study showed that when PDT treatment was curative, an increase in metastases was not observed, suggesting that only surviving cells can elicit conditions favorable to spreading after PDT and that dosimetry measurements could improve treatment $(14,31)$. In our study, PCNA expression of severely degenerated tumor cells was clearly inhibited by ALA-PDT, and the less damaged cells showed nearly the same expression level as control cells. PCNA is a cofactor for DNA polymerase $\delta$, which is required for DNA replication and cell proliferation (17). The surviving tumor cells with unchanged PCNA expression still have relative strong proliferation ability and may contribute to consequent tumor recurrence after ALA-PDT, as indicated by our study.

Whether PDT induces tumor metastasis remains controversial. Some reports have shown that PDT can markedly inhibit distant metastasis of tumors in vivo $(10,20,31)$, while others suggest that PDT can facilitate metastasis (31). In this research we did observe distant metastasis and blood vessel infiltration under the microscope in tumor tissue, indicating the metastatic characteristic behavior of CNE2 cells after ALA-PDT. The mechanism of tumor metastasis after PDT is not completely clear. At present, the common explanation to this is the up-regulation of angiogenic growth factor, such as VEGF following subcurative PDT (24-26). It has been well documented that PDT can induce severe hypoxia through over-consuming oxygen and damaging tumor vessel and blood flow (24), and that VEGF is up-regulated in hypoxia through transcription factors known as hypoxia-inducible factors (HIFs) that bind to the VEGF promoter (32). Several kinds of antiangiogenic agents have been applied in treating tumorbearing animal in combination with PDT, and these combination therapies have achieved better therapeutic outcomes $(24,25,31,33)$. Some previous reports have also shown that VEGF is up-regulated as early as in one day following PDT indicating that an increase in VEGF is an early event $(24,31)$. In our current study, expression of VEGF protein was slightly up-regulated at $24 \mathrm{~h}$ after ALA-PDT, but obviously downregulated 14 days after ALA-PDT, suggesting that VEGF may induce tumor metastasis immediately after PDT. Antiangio- genic treatments should be applied shortly after ALA-PDT, and late application with antiangiogenic agents is predicted to be ineffective at preventing metastasis. VEGF is not the only angiogenic factor that induces recurrence and metastasis of tumor after PDT, a broad-spectrum antiangiogenic agent, such as SU6668 is more effective than an anti-VEGF agent such as SU5416 in treating tumors in combination with PDT (33). The mechanism of VEGF changes after PDT is not completely clear. It has been suggested that the shift in VEGF is related to up-regulation of COX2 and the P38 mitogen-activated protein kinase pathway $(25,31)$. In the present study, VEGF was found to be strongly downregulated as late as 14 days after PDT, and the reasons for this need to be investigated further.

The present study suggests that incomplete killing of tumor cells is the main reason for tumor recurrence after ALA-PDT in nude mice bearing CNE2 cells. Early upregulation of VEGF may play an important role in tumor metastasis in treated mice.

\section{Acknowledgements}

This study was supported by GuangXi Natural Science Foundation of China (No. 0632007-1A). The authors express their gratitude to the staff of the department of GuangXi Experimental Center of Medical Sciences for excellent technical help and constructive criticism. We also take this opportunity to specifically thank Professor Xiong Wan and Dr Chapin Rodriguez for editing of the manuscript.

\section{References}

1. Shu CH, Shiau CY, Chi KH, Yen SH and Li WY: Salvage surgery for recurrent nasopharyngeal carcinoma in anterior marginal miss after radiotherapy. Otolaryngol Head Neck Surg 121: 622-626, 1999.

2. Wei WI and Sham JS: Nasopharyngeal carcinoma. Lancet 365: 2041-2054, 2005.

3. Cheli R, Addis F, Mortellaro CM, Fonda D, Andreoni A and Cubeddu R: Hematoporphyrin derivative photochemotherapy of spontaneous animal tumors: clinical results with optimized drug dose. Cancer Lett 23: 61-66, 1984.

4. Cheli R, Addis F, Mortellaro CM, Fonda D and Cubeddu R: Photodynamic therapy of spontaneous animal tumors using the active component of hematoporphyrin derivative (DHE) as photosensitizing drug: clinical results. Cancer Lett 38: 101-105, 1987.

5. Dougherty TJ, Gomer CJ, Henderson BW, et al: Photodynamic therapy. J Natl Cancer Inst 90: 889-905, 1998.

6. Brown SB, Brown EA and Walker I: The present and future role of photodynamic therapy in cancer treatment. Lancet Oncol 5: 497-508, 2004

7. Zhao SP, Tao ZD, Xiao JY, Peng YY, Yang YH, Zeng QS and Liu ZW: Clinical use of hematoporphyrin derivative and photoradiation therapy in nasopharyngeal carcinoma. Chin Med J (Engl) 101: 86-91, 1988.

8. Tong MC, van Hasselt CA and Woo JK: Preliminary results of photodynamic therapy for recurrent nasopharyngeal carcinoma. Eur Arch Otorhinolaryngol 253: 189-192, 1996.

9. Wang CP, Chang YL, Chen CT, Yang TH and Lou PJ: Photodynamic therapy with topical 5-aminolevulinic acid as a postoperative adjuvant therapy for an incompletely resected primary nasopharyngeal papillary adenocarcinoma: a case report. Lasers Surg Med 38: 435-438, 2006.

10. Lisnjak IO, Kutsenok VV, Polyschuk LZ, Gorobets OB and Gamaleia NF: Effect of photodynamic therapy on tumor angiogenesis and metastasis in mice bearing Lewis lung carcinoma. Exp Oncol 27: 333-335, 2005. 
11. Regula J, MacRobert AJ, Gorchein A, et al: Photosensitisation and photodynamic therapy of oesophageal, duodenal, and colorectal tumours using 5 aminolaevulinic acid induced protoporphyrin IX, a pilot study. Gut 36: 67-75, 1995.

12. Peng Q, Warloe T, Berg K, Moan J, Kongshaug M, Giercksky KE and Nesland JM: 5-Aminolevulinic acid-based photo-dynamic therapy. Clinical research and future challenges. Cancer 79: 2282-2308, 1997.

13. Yanase S, Nomura J, Matsumura Y, Nagata T, Fujii T and Tagawa T: Synergistic interaction of 5-aminolevulinic acidbased photodynamic therapy with simultaneous hyperthermia in an osteosarcoma tumor model. Int J Oncol 29: 365-373, 2006.

14. Momma T, Hamblin MR, Wu HC and Hasan T: Photodynamic therapy of orthotopic prostate cancer with benzoporphyrin derivative: local control and distant metastasis. Cancer Res 58: 5425-5431, 1998

15. Tanaka M, Kubo O, Tajika Y, Takahashi T, Suzuki S and Takakura K: Immunohistochemical evaluation of intracranial recurrent meningiomas: correlation of topoisomerase II alpha expression and cell proliferative potential. No To Shinkei 51: 1033-1039, 1999.

16. Mathews MB, Bernstein RM, Franza BR Jr and Garrels JI: Identity of the proliferating cell nuclear antigen and cyclin. Nature 309: 374-376, 1984

17. Wang LF, Chai CY, Kuo WR, Tai CF, Lee KW and Ho KY: The prognostic value of proliferating cell nuclear antigen (PCNA) and p53 protein expression in patients with advanced nasopharyngeal carcinoma. Acta Otolaryngol 126: 769-774, 2006.

18. Mayer A, Takimoto M, Fritz E, Schellander G, Kofler K and Ludwig $\mathrm{H}$ : The prognostic significance of proliferating cell nuclear antigen, epidermal growth factor receptor, and $\mathrm{mdr}$ gene expression in colorectal cancer. Cancer 71: 2454-2460, 1993.

19. Gomer CJ, Ferrario A and Murphree AL: The effect of localized porphyrin photodynamic therapy on the induction of tumour metastasis. Br J Cancer 56: 27-32, 1987.

20. Schreiber S, Gross S, Brandis A, Harmelin A, RosenbachBelkin V, Scherz A and Salomon Y: Local photodynamic therapy (PDT) of rat C6 glioma xenografts with Pd-bacteriopheophorbide leads to decreased metastases and increase of animal cure compared with surgery. Int J Cancer 99: 279-285, 2002.

21. Foultier MT, Vonarx-Coinsmann V, Cordel S, Combre A and Patrice T: Modulation of colonic cancer cell adhesiveness by haematoporphyrin derivative photodynamic therapy. J Photochem Photobiol B 23: 9-17, 1994.
22. Rousset N, Vonarx V, Eleouet S, Carre J, Kerninon E, Lajat Y and Patrice T: Effects of photodynamic therapy on adhesion molecules and metastasis. J Photochem Photobiol B 52: 65-73, 1999.

23. Bates DO and Curry FE: Vascular endothelial growth factor increases microvascular permeability via a $\mathrm{Ca}(2+)$-dependent pathway. Am J Physiol 273: H687-H694, 1997.

24. Ferrario A, von Tiehl KF, Rucker N, Schwarz MA, Gill PS and Gomer CJ: Antiangiogenic treatment enhances photodynamic therapy responsiveness in a mouse mammary carcinoma. Cancer Res 60: 4066-4069, 2000.

25. Solban N, Selbo PK, Sinha AK, Chang SK and Hasan T: Mechanistic investigation and implications of photodynamic therapy induction of vascular endothelial growth factor in prostate cancer. Cancer Res 66: 5633-5640, 2006.

26. Ferrario A, Von Tiehl K, Wong S, Luna M and Gomer CJ: Cyclooxygenase-2 inhibitor treatment enhances photodynamic therapy-mediated tumor response. Cancer Res 62: 3956-3961, 2002.

27. Peng Q, Warloe T, Moan J, Godal A, Apricena F, Giercksky KE and Nesland JM: Antitumor effect of 5-aminolevulinic acidmediated photodynamic therapy can be enhanced by the use of a low dose of photofrin in human tumor xenografts. Cancer Res 61: 5824-5832, 2001.

28. Babilas P, Schacht V, Liebsch G, Wolfbeis OS, Landthaler M Szeimies RM and Abels C: Effects of light fractionation and different fluence rates on photodynamic therapy with 5-aminolaevulinic acid in vivo. Br J Cancer 88: 1462-1469, 2003.

29. Remmele W and Stegner HE: Recommendation for uniform definition of an immunoreactive score (IRS) for immunohistochemical estrogen receptor detection (ER-ICA) in breast cancer tissue. Pathologe 8: 138-140, 1987.

30. Hamm AVeeck JBektas N, et al: Frequent expression loss of Inter-alpha-trypsin inhibitor heavy chain (ITIH) genes in multiple human solid tumors: a systematic expression analysis. BMC Cancer 8: 25, 2008.

31. Kosharskyy B, Solban N, Chang SK, Rizvi I, Chang Y and Hasan T: A mechanism-based combination therapy reduces local tumor growth and metastasis in an orthotopic model of prostate cancer. Cancer Res 66: 10953-10958, 2006.

32. Mitra S, Cassar SE, Niles DJ, Puskas JA, Frelinger JG and Foster TH: Photodynamic therapy mediates the oxygenindependent activation of hypoxia-inducible factor 1 alpha. Mol Cancer Ther 5: 3268-3274, 2006.

33. Zhou Q, Olivo M, Lye KY, Moore S, Sharma A and Chowbay B: Enhancing the therapeutic responsiveness of photodynamic therapy with the antiangiogenic agents SU5416 and SU6668 in murine nasopharyngeal carcinoma models. Cancer Chemother Pharmacol 56: 569-577, 2005. 